Volume 1 No. 1

Februari 2020

e-ISSN : 2721-9062

Website:

jurnal.umj.ac.id/index.php/JMMB

Email : jmmb.febumj@gmail.com jmmb@umj.ac.id

\title{
PENGARUH BUDAYA ORGANISASI DAN PENGEMBANGAN KARIR TERHADAP KOMITMEN KERJA KARYAWAN PADA PT. NUSA RAYA CIPTA
}

\author{
Dwi Oktariani $^{1 *}$ Tania Emilia Bahri ${ }^{2}$ \\ 1,2 Jurusan Manajemen, Fakultas Ekonomi dan Bisnis, Universitas Muhammadiyah Jakarta, Jl. KH. Ahmad \\ Dahlan, Jakarta, 15419 \\ *dwioktachandra@gmail.com
}

Diterima: 4 Februari 2020

DOI : 10.24853/jmmb.1.1.31-36
Direvisi: 9 Februari 2020

Disetujui: 12 Februari 2020

\begin{abstract}
ABSTRAK
Budaya di lingkungan kerja PT. NRC dirasa belum mendukung karyawan bekerja secara maksimal, hal ini teridentikasi dari sikap karyawan yang belum menerapkan kedisiplinan seperti datang tidak tepat waktu, pulang lebih awal, cara berpakaian kurang baik. Pada dasarnya PT. NRC merupakan perusahaan yang selalu menyediakan perlengkapan keamanan kerja seperti helm, jaket dan sepatu. Hal tersebut dilakukan oleh perusahaan dengan tujuan menciptakan rasa aman pada karyawan dengan pekerjaan yang dilakukannya. Namun dalam kenyataannya masih ada karyawan yang enggan menggunakannya di tempat kerja, hal tersebut menunjukkan bahwa masih ada karyawan yang kurang peduli terhadap keselamatan dirinya maupun terhadap kepentingan perusahaan, selain itu ditemukan kurangnya kegiatan rutin yang dapat mempererat hubungan atasan, bawahan, dan karyawan dengan karyawan yang lainnya, adanya sifat kecemburuan karyawan satu dengan yang karyawan yang lainnya dalam hal pembagian tugas ataupun bonus yang diberikan, ditunjukkan oleh sikap negatif karyawan kepada karyawan lainnya, hal ini yang menunjukkan budaya organisasi di PT. NRC kurang baik sehingga mempengaruhi sikap karyawan dalam menghadapi resiko dan berpengaruh kepada komitmen karyawan karena karyawan merasa kurang nyaman dengan permasalahan tersebut dalam hal melakukan pekerjaan dan hal itu sangat mempengaruhi sikap dan kinerja serta ketersediaan untuk tetap tinggal di perusahaan tersebut, dan akan membuat karyawan memilih untuk mencari budaya perusahaan yang lebih baik dan berinovasi.
\end{abstract}

Kata Kunci: Komitmen Kerja, Pengembangan Karir, Budaya Organisasi, Regresi Linear Berganda

\begin{abstract}
The work environment culture of PT. NRC is felt not so support the employees working optimally, this is identified from the employees attitude who have not implemented discipline such as not arriving on time, leaving early, undress well. Basically PT. NRC is a company that always provides work safety equipment such as helmets, jackets and shoes. This is done by the company with the aim to creating a sense of security for employees from what they do. But in reality there are still employees who are reluctant to use it in the workplace, it shows that there are still employees who are less concerned about their own safety or what company focus on, other than that there is a lack of routine activities that can strengthen relations between superiors, subordinates, and employees with employees or others, the existence of employee jealousy with other employees in terms of the distribution of tasks or bonuses given, is shown by the negative attitude of employees to other employees. It shows the organizational culture at PT. NRC is not good enough, so its affect to the employees attitudes for dealing their risk and also affects employees commitment because their feel uncomfortable with the problem in terms from doing work. Then it greatly affects the attitude and performance, also availability to remain in the company, so it will make employees choose to find a better company culture or an innovation.
\end{abstract}

Keywords: Work Commitment, Career Development, Organizational Culture, Multiple Linear Regression 


\section{PENDAHULUAN}

PT. NUSA RAYA CIPTA, umumnya dikenal sebagai NRC, adalah perusahaan yang bergerak di jasa kontraktor umum dengan pelayanan yang lengkap dan menyeluruh meliputi : perencanaan, desain hingga pembangunan (plan, design and build). Perusahaan ini didirikan pada 17 September 1975 sebagai kelanjutan dari PT. National Roadbuilders \& Construction Co. yang didirikan oleh Ir. Benjamin Arman Suriajaya dan Ir. Marseno Wirjosaputro pada tanggal 25 November 1968. PT. Nusa Raya Cipta adalah salah satu anak perusahaan dari PT. Surya Semesta Internusa Tbk. (SSIA). Sejak 1992 PT. Kantor pusat Nusa Raya Cipta berada di Gedung Graha Cipta lantai 2, J1. Saya Panjaitan No. 40, Jakarta Timur dan memiliki cabang di Medan, Semarang, Surabaya, Denpasar, dan Balikpapan.

Berdasarkan observasi awal, budaya di lingkungan kerja PT. NRC dirasa belum mendukung karyawan bekerja secara maksimal, hal ini teridentikasi dari sikap karyawan yang belum menerapkan kedisiplinan seperti datang tidak tepat waktu, pulang lebih awal, cara berpakaian kurang baik. hal ini yang menunjukkan budaya organisasi di PT. NRC kurang baik sehingga mempengaruhi sikap karyawan dalam menghadapi resiko dan berpengaruh kepada komitmen karyawan karena karyawan merasa kurang nyaman dengan permasalahan tersebut dalam hal melakukan pekerjaan dan hal itu sangat mempengaruhi sikap dan kinerja serta ketersediaan untuk tetap tinggal di perusahaan tersebut, dan akan membuat karyawan memilih untuk mencari budaya perusahaan yang lebih baik dan berinovasi. Selain itu, dalam perusahaan ini program pengembangan karir belum berjalan dengan baik hal ini ditunjukkan dari jenjang karir atau pengembangan karir karyawan yang dilakukan dalam jangka waktu yang cukup lama dan fenomena yang terjadi dalam perusahaan ini adalah kurang meratanya pelatihan dan pendidikan yang menyebabkan karyawan sulit melakukan pengembangan karir karena belum ada pengetahuan dan keterampilan yang diperbarui, hal ini tentu penting guna meningkatkan mutu sumber daya manusia dan meningkatkan keterampilan dan produktivitas sumber daya manusia. Faktor inilah yang dapat mengurangi rasa komitmen karyawan karena karyawan merasa kurangnya fasilitas dari perusahaan untuk mengembangkan potensi diri, karir, keterampilan serta penghasilan, sehingga karyawan memilih untuk mengubah karir nya dengan cara mencari karir baru yang dapat mengembangkan potensi, karir, keterampilan serta penghasilan yang lebih baik dan meningkat.

Keberadaan komitmen dalam diri karyawan bukan hanya berasal dari individu yang bersangkutan tetapi dapat dipengaruhi oleh faktor-faktor lain yang berhubungan dengan individu tersebut. Faktor-faktor yang dapat memengaruhi komitmen karyawan adalah budaya organisasi. Pesatnya laju perubahan lingkungan seperti saat ini menyadarkan organisasi akan semakin pentingnya adaptabilitas, yakni kemampuan untuk tanggap akan lingkungan eksternal, pelanggan internal, dan pelanggan eksternal dengan cara menerjemahkan permintaan lingkungan bisnis menjadi tindakan agar perusahaan bertahan, bertumbuh, dan berkembang (Robbins, 2013). Menurut Dyne (2005) salah satu indikator dalam menciptakan budaya organisasi yang baik adalah menciptakan rasa aman dengan pekerjaan. Hal ini akan meningkatkan komitmen kerja karyawan. Senada dengan hal di atas, Robbins (2013), mengatakan bahwa budaya organisasi memiliki keterkaitan yang erat dengan komitmen kerja karyawan. Apabila persepsi karyawan terhadap budaya dalam suatu organisasi baik, maka karyawan akan merasa puas terhadap pekerjaannya. Sebaliknya, apabila persepsi karyawan terhadap budaya dalam suatu organisasi tidak baik, maka karyawan cenderung tidak puas terhadap pekerjaannya.

Banyak organisasi yang menghadapi persaingan dengan membangun komitmen dengan para karyawan dalam upaya meningkatkan kualitas. Berdasarkan masalah dan fenomena yang telah dijelaskan, maka penulis merumuskan tujuan dari penelitian ini: (1) menganalisis bagaimana pengaruh budaya organisasi terhadap komitmen karyawan pada perusahaan, (2) menganalisis secara bersamasama pengaruh dari pengembangan karir yang cukup lama terhadap komitmen karyawan pada perusahaan dan (2) menganalisis bagaimana budaya organisasi dan pengembangan karir 
Dwi Oktariani, Tania Emilia bahri : Pengaruh Budaya Organisasi dan pengembangan Karir Terhadap Komitmen Kerja Karyawan Pada PT. Nusa raya Cipta.

berpengaruh terhadap komitmen karyawan di PT. NRC.

\section{METODE PENELITIAN}

Penelitian ini menggunakan penelitian yang bersifat kuanitatif berdasarkan hasil olahan data spss dengan metode regresi linear berganda yang bertujuan untuk mengetahui pengaruh terhadap budaya organisasi (X1) dan pengembangan karir (X2) terhadap komitmen kerja karyawan (Y) di PT.NRC. Pendekatan kuantitatif dengan spesifikasinya adalah sistematis, terencana, dan terstruktur dengan jelas berdasarkan hasil nyata data kuisioner yang diperoleh dari responden. Penelitian ini juga di dukung dengan metode deskriptif analisis, agar dapat menggambarkan hasil interpertasi data hasil olahan kuisioner dengan teori yang ada.

Dalam penelitian ini, seluruh populasi dijadikan sampel atau yang disebut sampel jenuh yaitu sebanyak 60 orang karyawan, karena jumlah populasi kurang dari 100 orang. 60 orang karyawan yang menjadi responden adalah karyawan PT.NRC dengan porposi jumlah laki-laki sebanyak 54 orang dan perempuan sebanyak 6 orang.

Teknik pengumpulan data dalam penelitian ini dengan melakukan penyebaran kuisioner secara langsung dalam skala likert dengan lima indikator penelian, mulai dari sangat rendah, rendah, netrak, puas dan sangat puas. Selain kuisioner, peneliti juga melakukan pengamatan langsung di PT.NRC yang berada di Kemang, Jakarta selama kurun waktu November 2019 - Januari 2020 untuk mendapatkan hasil kuisioner yang valid dan reliabel. Sehingga sebelum kuisioner ini disebarkan secara langsung kepada 60 karyawan sudah teruji instrument kuisioner nya dalam uji validitas data dan uji reliabelitas. Teknik analisis data menggunakan metode regresi linier berganda dengan program software SPSS for windows. Proses pengulahan data adalah (1) uji validitas dan reliabelitas data, (2) Uji Asumsi Klasik, dan (3) Uji regresi berganda untuk melihat pengaruh positif dan negative dari variabel dependen terhadap variabel independen. Uji $t$ dan Uji-F akan tetap dilakukan, hanya untuk melihat apakah memiliki pengaruh signifikan atau tidak bagi sampel (responden) meskipun tidak diperlukan.

\section{HASIL DAN PEMBAHASAN}

Didirikan pada tanggal 17 September 1975, PT Nusa Raya Cipta. Tbk adalah perusahaan yang bergerak di sektor jasa konstruksi. Perseroan juga memiliki kompetensi mendalam dalam bidang pembangunan infrastruktur. Dengan lebih dari 40 tahun pengalaman di bidang konstruksi, Perseroan terus mengembangkan jaringan kantor cabang yang hingga akhir tahun 2018, Perseroan memiliki 4 kantor cabang yang berlokasi di Medan, Semarang, Surabaya, dan Denpasar. Perseroan menjadi perusahaan publik melalui Initial Public Offering (IPO) padatahun 2013 di Bursa Efek Indonesia dengan kode saham NRCA. Sejak tanggal pendirian, Perseroan belum pernah mengalami perubahan nama. Berdasarkan teori yang yang ada, teori yang mendukung fenomena dari penelitian ini adalah continuance commitment. Teori ini menggambarkan bagaiaman kecenderungan individu untuk tetap menjaga komitmen karyawan pada organisasi karena tidak ada hal lain yang dapat dikerjakan di luar itu. Hal ini sejalan dengan yang terjadi pada karyawan PT.NRC, khususnya karyawan laki-laki yang memiliki porsi kerja lebih banyak dilapangan. Jika seorang karyawan yang sudah terbiasa melakukan pekerjaan di luar kantor seperti dalam industri konstruksi maka akan berat bagi mereka jika harus memulai kebiasaan baru untuk bekerja di dalam ruangan. Individu dengan continuance commitment yang tinggi akan bertahan dalam organisasi, bukan hanya karena alasan emosional, tapi karena adanya kesadaran dalam individu tersebut akan kerugian besar yang dialami jika meninggalkan organisasi. Salah seorang karyawan pada PT. NRC membenarkan hal ini, karena mereka sudah merasa cukup hanya dengan fasilitas gaji yang diterima, yang mungkin saja tidak akan mereka dapatkan jika mereka bekerja dalam perusahaan lain. Individu dengan continuance commitment yang tinggi akan lebih bertahan dalam organisasi dibandingkan yang rendah.

Budaya organisasi pada PT. NRC di iringi dengan teori yang fokus kepada people oriented, Orientasi manusia menjelaskan sejauh mana keputusan manajemen memperhitungkan efek hasil kepada orangorang di dalam organisasi tersebut. Seperti yang sudah dijelaskan di atas, bahwa keselamatan karyawan yang bekerja di luar lapangan adalah fokus utama bagi perusahaan, 
hal ini sejalan dengan teori yang menggambarkan bahwa bagaimana nilai dari budaya organisasi perusahaan akan memberikan efek pasti bagi orang yang meyakini nya. Sehingga bisa dikita simpulkan bahwa budaya organisasi pada PT.NRC secara teori dan olah data memberikan hasil yang sesuai dengan fenomena yang terjadi pada saat penelitian. Ini membuktikan bahwa tidak selamanya ketika seorang karyawan bekerja dalam perusahaan, hal pertama yang menjadi pencapaian bagi mereka adalah bagaiamana perusahaan bisa membantu mereka dalam mendapatkan jenjang karir yang baik.

Variabel X2 yaitu pengembangan diri sendiri, tidak memberikan pengaruh yang berarti, karena berdasarkan pengamatan yang peneliti lakukan bahwa masih terdapat karyawan yang pengembangan karir nya sangat terlambat bahkan tidak berkembang sama sekali. Salah satu penyebab hal ini bisa terjadi adalah karena PT.NRC bergerak di industri manufakur (konstruksi) dimana jenjang karir tidak menjadi fokus khusus bagi karyawan yang akan atau sedang bekerja disana. PT.NRC memiliki proposi karyawan berdasarkan gender, laki-laki dan perempuan. Perbandingan gender yang bisa dilihat melalui sumber data sangat besar, karena bagi PT.NRC sendiri, lebih banyak dibutuhkan karyawan laki-laki agar bisa bekerja dilapangan. Pada kenyataan nya, jenis pekerjaan pada industri seperti ini tidak memerlukan jenjang karir yang pasti seperti di kantoran. Hal ini semakin memperjelas bahwa variabel X1 memberikan gambaran mengapa responden memiliki alasan untuk tetap bekerja di PT.NRC meskipun perusahaan tersebut tidak memberikan peluang karir yang menjanjikan. Sedangkan sisanya sebesar 38,8\% dipengaruhi atau dijelaskan oleh variabel lain yang tidak dimasukkan dalam model penelitian ini seperti kebijakan kompensasi dan faktor pribadi karyawan tersebut. Berdasarkan Uji-t, dapat kita simpulkan bahwa varibel pengembangan karir (X2) tidak memiliki pengaruh yang signifikan (negatif). Berdasarkan data kuisioner yang diisi oleh karyawan sebagai responden, memunculkan fakta yang terjadi di lapangan benar adanya. Hal ini disebabkan karena proses pengembangan karir pada PT.NRC tidak menjadi kebutuhan utama bagi perusahaan. Jika dilihat berdasarkan rasio dari para karyawan, porposi pekerja laki-laki sebanyak 52 orang sedangkan perempuan sebanyak 6 orang. PT.NRC yang bergerak dalam industri manufaktur membutuhkan lakilaki untuk bekerja di lapangan, sedangkan tenaga kerja perempuan bertugas hanya sebagai admin di kantor. Perbedaan jenis pekerjaan dalam industri manufaktur menuntut perusahaan untuk mengesampingkan pengembangan karir ke jenjang lebih pasti. Jika dibandingkan dengan proses pengembangan karir yang dilakukan oleh industri jasa seperti perbankan, maka PT.NRC tidak melakukan hal yang merugikan bagi karyawan. PT.NRC memberikan berbagai fasilitas dalam bentuk lain yang lebih menjanjikan dibandingkan dengan program pengembangan karir. Salah satu fasilitas yang lebih menjanjikan adalah kompensasi gaji. Pemberian kompensasi gaji ini disesuaikan dengan seberapa berat tanggung jawab pekerjaan yang diberikan oleh perusahaan kepada kita. Besarnya gaji yang diterima lebih menjanjikan dibandingkan program pengembangan karir. Karyawan PT.NRC juga membenarkan bahwa program pengembangan karir tidak menjadi suatu hal yang dijadikan alasan bagi mereka untuk berkomitmen dan terus bekerja di PT. NRC.

Dari hasil perhitungan uji $\mathrm{f}$ diperoleh nilai Fhitung > Ftabel $(43,378>3,17)$ dan nilai signifikan 0,000 lebih kecil dari nilai nilai nyata 0,05. Dengan demikian dapat disimpullkan bahwa Ho ditolak dan menerima $\mathrm{Ha}$, artinya terdapat pengaruh positif dan signifikan antara variabel Budaya Organisasi dan Pengembangan Karir secara bersama-sama terhadap Komitmen Kerja Karyawan. Meskipun secara parsial, keduanya memiliki pengaruh secara bersama-sama tapi mereka memiliki hubungan yang berbeda, hubungan ini digambarkan dengan positif dan negative. Dimana budaya organisasi memberikan hubungan yang positif dan berpengaruh bagi perusahaan sedangkan pengembangan karir memberikan hubungan yang negatif dan berpengaruh bagi perusahaan. 


\section{KESIMPULAN}

1. Budaya organisasi berpengaruh positif dan signifikan terhadap komitmen organisasi. Hal ini bisa dilihat berdasarkan nilai dari Uji-t dari variabel budaya organisasi (X1) hal ini menunjukkan bahwa peningkatan budaya organisasi akan mengakibatkan meningkatnya komitmen organisasi pada karyawan di PT.NRC. Adapun yang paling dominan dalam mengukur budaya organisasi direfleksikan dengan dimensi people orientation. Dimana fokus perusahaan adalah karyawan, agar selalu merasa berada dalam kondisi yang secure. Sementara faktor yang paling dominan dalam mengukur komitmen organisasi direfleksikan oleh continuance commitment terutama dalam hal tingkat loyalitas pada perusahaan yang timbul akibat rasa keterikatan secara emosional akibat perhatian dari perusahaan kepada karyawan.

2. Pengembangan karir berpengaruh negatif dan signifikan terhadap komitmen kerja. Hasil yang diperoleh berdasarkan data SPSS bahwa pengembangan karir (X2) memiliki nilai yang tidak signifikan melalui Uji-t. Hal ini menunjukkan bahwa suatu program pengembangan karir pada karyawan PT.NRC tidak berpengaruh (negatif) dalam mengukur komitmen mereka. Keinginan karyawan untuk memiliki komitmen dalam perusahaan justru tidak didasari oleh proses pengembangan karir yang dijanjikan dalam suatu pekerjaan. Hal ini lah yang mengakibatkan pengaruh dari X2 negatif terhadap Y.

3. Budaya organisasi dan pengembangan karir secara simultan berpengaruh signifikan terhadap komitmen kerja karyawan, hal ini menunjukkan hubungan bahwa keinginan berkomitmen seorang karyawan dapat ditentukan oleh bagaimana budaya organisasi tersebut menjadi nilai dan mengikat perasaan sehingga menimbulkan loyalitas. Kedua varibael ini secara simultan akan mengakibatkan menjadi faktor penentu bagi karyawan agar berkomitmen, hal ini ditunjukkan dengan kontribusi (R2) sebesar $61 \%$, lalu secara parsial budaya organisasi merupakan variabel yang paling dominan dalam menentukan komitmen kerja seorang karyawan.

\section{DAFTAR PUSTAKA}

Stephen, Robbins \& Judge, Timothy A. 2013. Organizational Behavior Edition 15. New Jersey : Pearson Education.

Dyne,Van dan Graham J.W. 2005. Organizational Citizenship Behavior, Construct Redefintion Measurement and Validatoion. Academic Manajemen Jurnal.

Mathis, L Robert \& Jackson John. 2006, Human Resource Management. Jakarta: Salemba Empat

Yulan, Innocentius Bernarto. 2017. Pengaruh self-efficacy, budaya organisasi dan motivasi kerja terhadap komitmen kerja. DeReMa Jurnal Manajemen. Vol. 12 No. 1, Mei 2017

Mangkunegara, A.P. (2012). Evaluasi Disiplin Sumber Daya Manusia. Bandung: Refika Adhitama.

Jufrizen. 2015. Pengaruh Pengembangan Karir dan Kompensasi Terhadap Komitmen Organisasi Dengan Kepuasan Kerja Sebagai Variabel Intervening Pada PT. Perkebunan Nusantara III (PERSERO) Medan. Jurnal Ilmiah Manajemen dan Bisnis Vol. 15, No. 01, April 2015.

Sugiyono. 2012. Metode Penelitian Kuantitatif kualitatif dan R\&D. Bandung: Alfabeta

Veithzal, Rivai. 2008. Manajemen Sumber Daya Manusia untuk Perusahaan. Jakarta : PT. Raja Grafindo Persada.

Ghozali, Imam. 2009. Aplikasi Analisis Multivariate Dengan Program IBM SPSS, Edisi Keempat. Semarang : Univesitas Diponegoro.

Meyer, J.P., Stanley, D.J., Herscovitch, L. and Topolnytsky, L. (2002), "Affective, continuance, and normative commitment to the organization: a meta-analysis of antecedents, correlates, and consequences", Journal of Vocational Behavior, Vol. 61 No. 1, pp. 20-52. Stephen, Robbins \& Judge, Timothy A. 2013. Organizational Behavior Edition 15. New Jersey : Pearson Education. 